\title{
The applicability of solid state characterization and analytical techniques for reference chemical substance certification: Resolution of the Collegiate Board (RDC) 166/2017 by National Health Surveillance Agency (ANVISA)
}

\author{
Renan Marcel Bonilha Dezena iD \\ Preformulation Specialist in the Pharmaceutical Industry
}

\section{BACKGROUND}

Reference chemical substances called primary reference are used which are marketed by official compendia both nationally and internationally in the pharmaceutical industry as a tool for identification and quantification during pre-formulation, development/analytical validation and quality control studies.

The reference or primary standards are almost always imported and resold in the Brazilian market as a consequence, increasing the cost in relation to the sample amount (little amount of mass in mg per bottle).

On July 24, 2017, the National Health Surveillance Agency (ANVISA) published the Resolution of the Collegiate Board (RDC) number 166, which deals with the validation of analytical methods. The Chapter III of this resolution is intended for reference chemical substances and, in Art. 14 § 1, the RDC 166/2017 allows the use of characterized reference chemical substances in the analytical validations.

The characterization study is planned according to the chemical structure of the substance to be characterized and within this new regulation, solid-state characterization and analytical chemistry stands out as an essential ally corroborating with the evolution of the number of publications in the literature regarding this subject in the google scholar database as shown in Figures 1 and 2 [1-15].

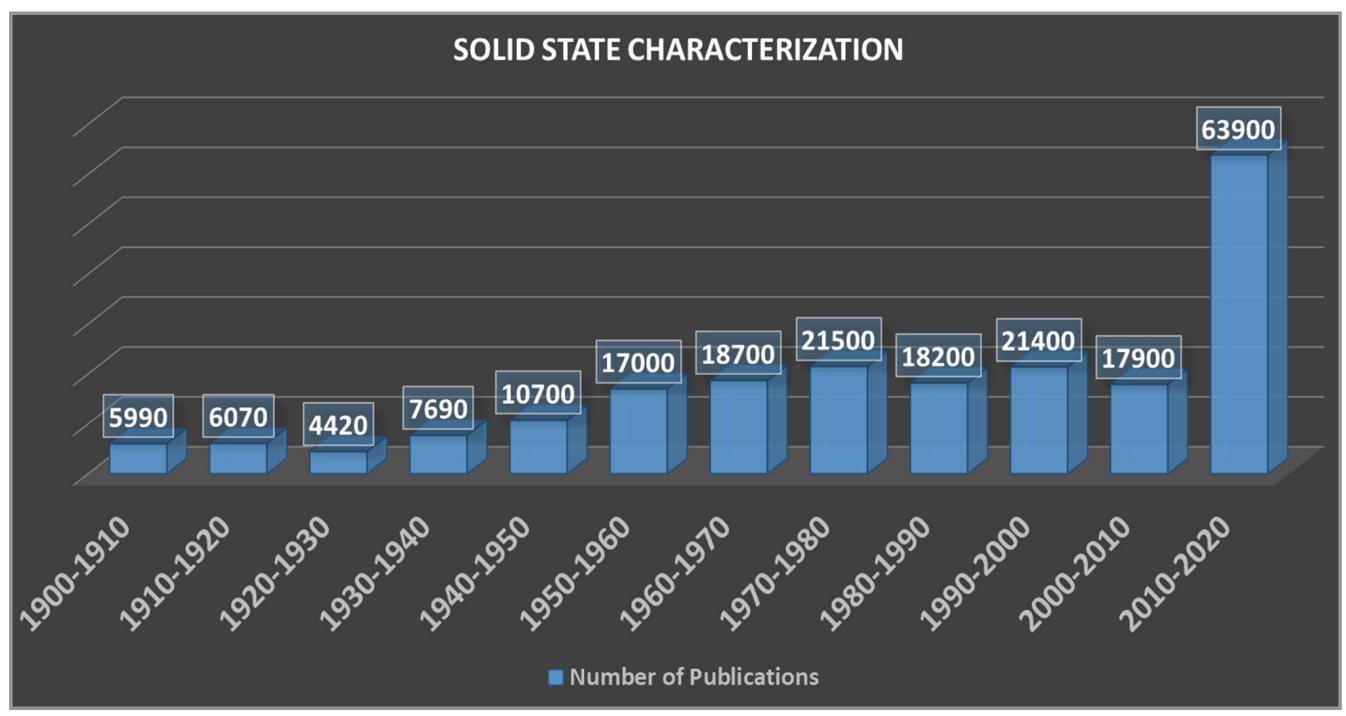

Figure 1. Evolution of the number of references (scientific articles), from 1900 to 2020, containing the concept "solid state characterization" in the google scholar database.

Cite: Dezena, R. M. B. The applicability of solid state characterization and analytical techniques for reference chemical substance certification: Resolution of the Collegiate Board (RDC) 166/2017 by National Health Surveillance Agency (ANVISA). Braz. J. Anal. Chem., 2021, 8 (33), pp 13-18. doi: http://dx.doi.org/10.30744/brjac.2179-3425.letter-rmbdezena-N33 


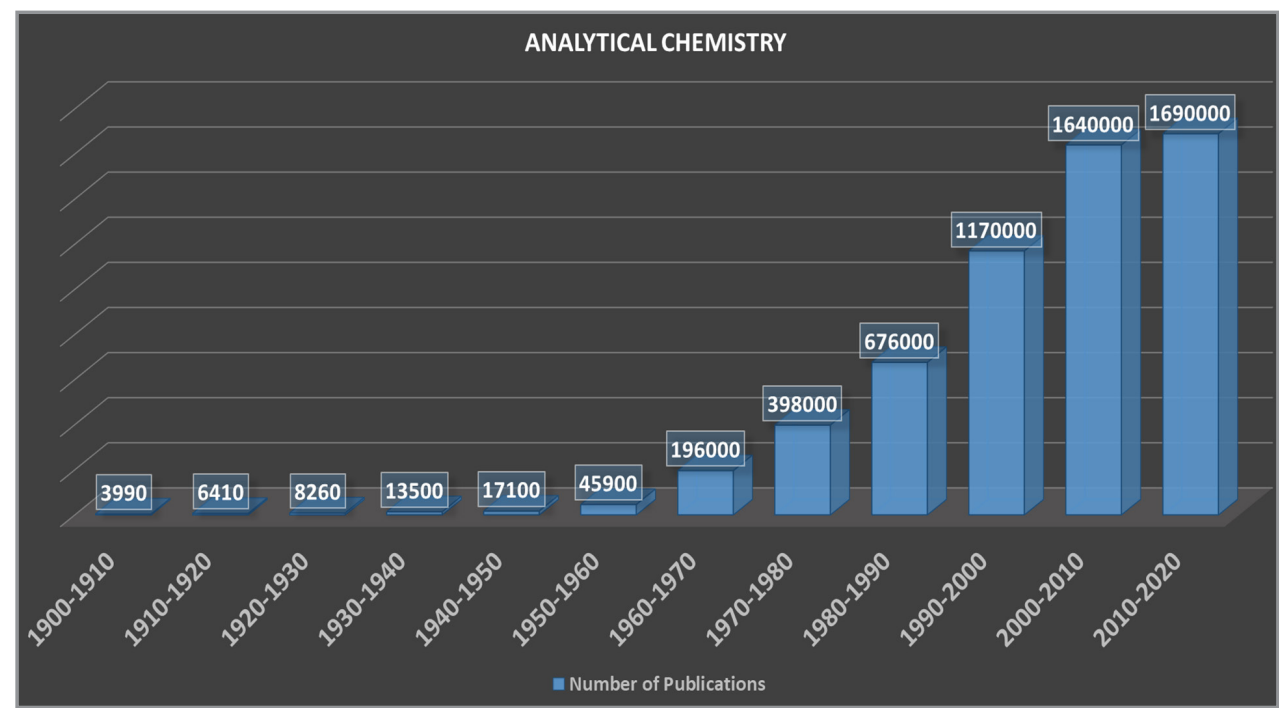

Figure 2. Evolution of the number of references (scientific articles), from 1900 to 2020 , containing the concept "analytical chemistry" in the google scholar database.

In Figures 3 and 4, a bibliometric map was performed due to its important role in the evaluation of scientific production worldwide, since its indicators can portray the behavior and progress of the field of knowledge [16].

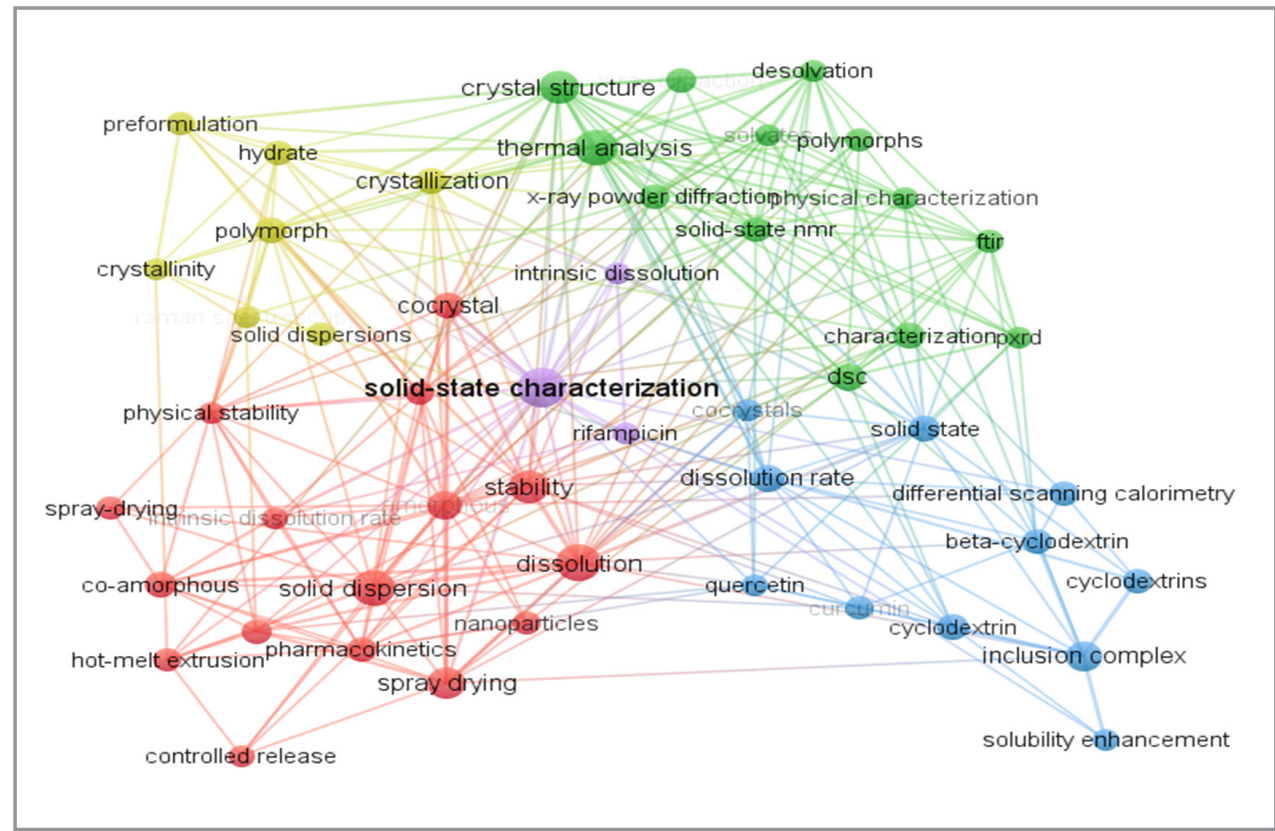

Figure 3. Network visualization map of 50 main items from the 1,029 articles exported from the Web of Science database using the concept "solid state characterization" on 03/29/2021 (VOSviewer software, version 1.6.16). 


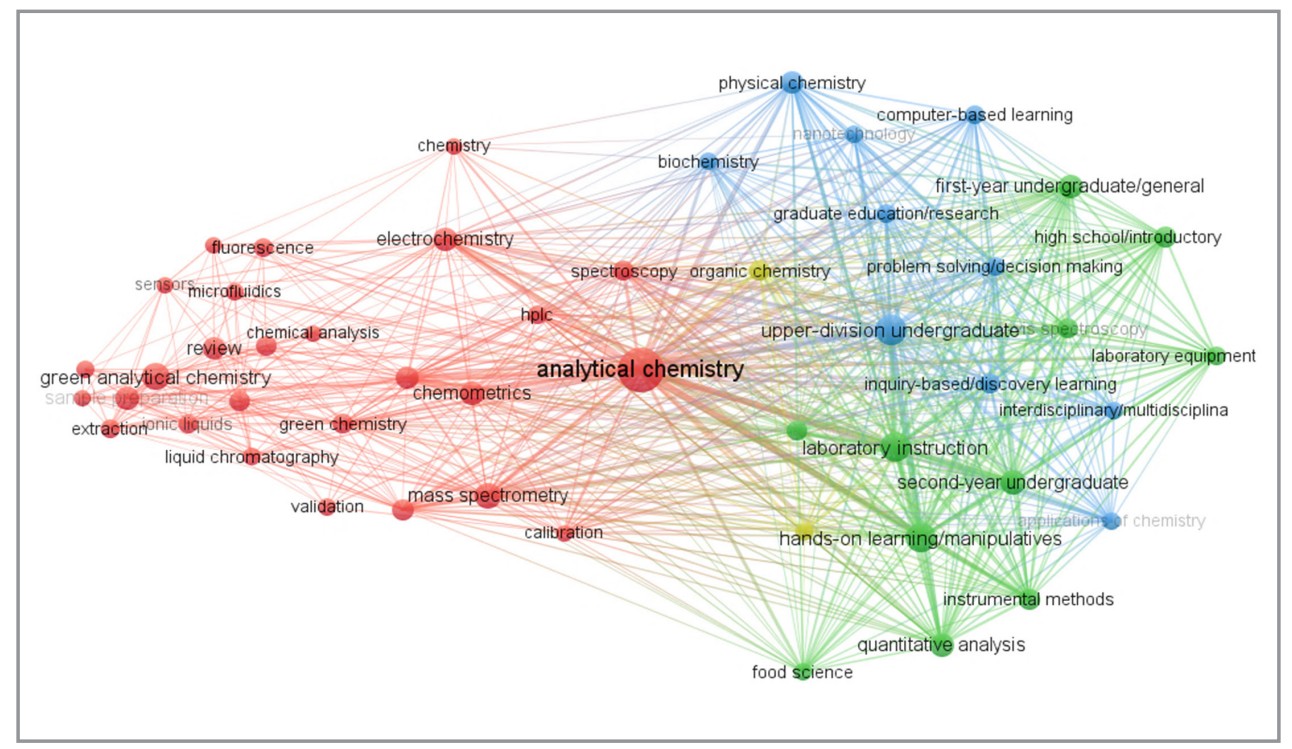

Figure 4: Network visualization map of 50 main items from the 11,712 articles exported from the Web of Science database using the concept "analytical chemistry" on 03/29/2021 (VOSviewer software, version 1.6.16).

\section{High performance liquid chromatography (HPLC)}

The HPLC enables the separation, identification and quantification of chemical compounds in complex mixtures and matrices [17-18]. The compounds of a mixture are distributed by the flow of the mobile phase through a column with a stationary phase and the separations are based on differences in migration speed due to the affinity of the components between the mobile phase and the stationary phase [1718]. Separations are achieved by partition, adsorption, ion exchange, exclusion by size, stereochemical interactions, depending on the type of stationary phase used [17-18].

The studies that are normally conducted are identification; purity, related substances, impurities and assay [17-18].

\section{Mass spectrometry (MS)}

The MS allows analyzing the molecules through the mass / charge ratio $(\mathrm{m} / \mathrm{z})$ of the ions of these compounds in the gaseous state and consequently enabling the characterization of their chemical structure [19].

\section{Differential scanning calorimetry (DSC)}

The DSC performs the measurement of the physical-chemical properties of materials according to difference between the temperature of the reference and the sample, at a constant heat flow in a controlled atmosphere normally nitrogen or oxygen [20]. The technique assesses phenomena, such as melting temperature, recrystallization, polymorphism, desolvation, dehydration, evaporation, decomposition, crystallinity, sublimation, glass transitions, pyrolysis, solid-solid interactions (eutectic mixture) and purity, and such data are extremely relevant in characterization of substances [20].

\section{Thermogravimetric analysis (TGA)}

The TGA is used to determine the loss of mass of a sample due to variations in temperature, time and type of atmosphere (nitrogen and oxygen) [21]. Additional data are provided through the changes that heating produces in the mass of substances, making it possible to establish studies regarding the degree of hydration of the molecules, composition, chemical reactions, oxidation induction time, isothermal drying, ash content, filler content, separation of vaporization and decomposition [21]. 


\section{X-ray powder diffraction (XRPD)}

The XRPD is a specific non-destructive crystallographic technique applied for the qualitative or quantitative determination of a sample's crystalline phases, offering information regarding crystal structure, polymorphism, lens size, preferred orientation, and layer thickness [22].

\section{Fourier-transform infrared spectroscopy (FTIR)}

The FTIR is responsible for the identification of an organic compound, for the presence of specific bands of functional groups of the molecule through the absorption of infrared radiation $\left(400-4000 \mathrm{~cm}^{-1}\right)$ [23].

\section{Nuclear magnetic resonance (NMR)}

The NMR is a spectroscopic technique that makes it possible to determine the properties of a molecule through the correlation of energy absorbed with the frequency in the megahertz $(\mathrm{MHz})$ range [24].

\section{Elemental analysis (C, H, N, S)}

It aims to elucidate exactly what are the elements that make up a sample (qualitatively) and in what proportion they appear in the molecular formula (quantitatively), mainly through the levels of carbon, hydrogen, nitrogen and sulfur [25].

\section{Optical rotation}

Some molecules after solubilization have the ability to rotate in contact with polarized light, especially those with chiral centers (carbon atoms with four different substituents) [26]. Molecules that rotate clockwise are called dextrogins while those that rotate counterclockwise are called levogiras [26].

\section{SUMMARY}

Through RDC 166/2017 approval, the characterization of the solid state has become indispensable within this new scenario providing greater access and autonomy for the pharmaceutical industries regarding the possibility of characterization of raw materials and use during the stages of development and analytical validations as well as in quality control of active pharmaceutical ingredients and finished products.

\section{Acknowledgments}

I would like to thank Daniel Fernandes Andrade and Edenir Rodrigues Pereira-Filho from the Group of Applied Instrumental Analysis (GAIA), Department of Chemistry, Federal University of São Carlos (UFSCar), 13565-905 São Carlos - SP, Brazil for the scientific contribution regarding bibliometrics topic and for the files exported from the Web of Science database.

\section{REFERENCES}

1. Dezena, R. M. B. Br. J. Anal. Chem., 2017, 4 (16), pp 8-9.

2. Dezena, R. M. B.; Malta Jr., J. D. S. Br. J. Anal. Chem., 2017, 4 (15), pp 19-26.

3. Dezena, R. M. B.; Malta Jr., J. D. S.; Meurer, E. C.; Eberlin, M. N. Br. J. Anal. Chem., 2017, 4 (15), pp 27-34.

4. Dezena, R. M. B. Braz. J. Anal. Chem., 2020, 7 (26), pp 12-17 (http://dx.doi.org/10.30744/ brjac.2179-3425.letter.rmbdezena.N26).

5. Dezena, R. M. B.; Malta Júnior, J. S.; de Godoy, F. P.; Smith, T. Braz. J. Anal. Chem., 2020, 7 (28), pp 11-19 (http://dx.doi.org/10.30744/brjac.2179-3425.N28-letter).

6. Dezena, R. M. B.; Coelho Silva, R. C.; Luiz, G. F. Braz. J. Anal. Chem., 2019, 6 (25), pp 10-12 (http:// dx.doi.org/10.30744/brjac.2179-3425.letter.rmbdezena.N25).

7. Dezena, R. M. B.; Mauri, R.; Barros, F. A. P.; Rosa, P. C. P. J. App. Biol. Biotech., 2019, 7 (02), pp 64-70 (http://dx.doi.org/10.7324/JABB.2019.70212).

8. Dezena, R. M. B. Braz. J. Anal. Chem., 2021, 8 (30), pp 11-13 (http://dx.doi.org/10.30744/ brjac.2179-3425.letter-rmbdezena-N30). 
9. Jiménez-Reyes, M.; Tenorio, D.; García-Rosales, G.; Jiménez-Becerril, J.; Luna-Castro, G. E. Braz. J. Anal. Chem., 2021, 8 (30), pp 29-42 (http://dx.doi.org/10.30744/brjac.2179-3425.AR-51-2020).

10. Mohamed, A. A. E. Braz. J. Anal. Chem., 2021, 8 (30), pp 43-58 (http://dx.doi.org/10.30744/ brjac.2179-3425.AR-52-2020).

11. Rajendraprasad, N.; Basavaiah, K. Braz. J. Anal. Chem., 2020, 7 (28), pp 44-69 (http://dx.doi. org/10.30744/ brjac.2179-3425.AR-23-2020).

12. Al-Kharosi, A. S.; Al-Sabari, W. A.; AL-Shidhani, F. H.; Alfarsi, S. A.; Taha, S. M. Braz. J. Anal. Chem., 2020, 7 (26), pp 18-26 (http://dx.doi.org/10.30744/brjac.2179-3425.AR-23-2019).

13. Lourdes, A. M. F. O.; Cuin, A.; Delbem, I. D.; Campos, N. S.; Sousa, R. A.; Ciminelli, V. S. T.; Silva, J. C. J. Braz. J. Anal. Chem., 2020, 7 (26), pp 36-50 (http://dx.doi.org/10.30744/brjac.2179-3425.AR-34-2019).

14. Hakme, E.; Herrmann, S. S.; Poulsen, M. E. Braz. J. Anal. Chem., 2020, 7 (26), pp 51-77 (http://dx.doi. org/10.30744/brjac.2179-3425.AR-36-2019).

15. Abe-Matsumoto, L. T.; de Araújo, Y. A. Braz. J. Anal. Chem., 2020, 7 (27), pp 14-19 (http://dx.doi. org/10.30744/brjac.2179-3425.AR-38-2019).

16. Araújo, A. S.; Andrade, D. F.; Babos, D. V.; Castro, J. P.; Garcia, J. A.; Sperança, M. A.; Gamela, R. R.; Machado, R. C.; Costa, V. C.; Guedes, W. N.; et al. Braz. J. Anal. Chem., 2021, 8 (30), pp 14-28 (http:// dx.doi.org/10.30744/ brjac.2179-3425.RV-27-2020).

17. Trontelj, J.; Vovk, T.; Bogataj, M.; Mrhar, A. Pharmacol. Res., 2005, 52 (4), pp 334-339 (https://doi. org/10.1016/j.phrs.2005.05.007).

18. Bueno, L. M.; Manoel, J. W.; Giordani, C. F. A.; Mendez, A. S. L.; Volpato, N. M.; Schapoval, E. E. S.; Sttepe, M.; Garcia, C. V. Eur. J. Pharm. Sci, 2017, 97, pp 22-29 (https://doi.org/10.1016/j. ejps.2016.11.004).

19. Beccaria, M.; Cabooter, D. Analyst, 2020, 145(4), pp 1129-1157 (https://doi.org/10.1039/C9AN02145K).

20. Leyva-Porras, C.; Cruz-Alcantar, P.; Espinosa-Solís, V.; Martínez-Guerra, E.; Piñón-Balderrama, C. I.; Compean Martínez, I.; Saavedra-Leos, M. Z. Polymers, 2020, 12 (1), pp 1-21 (https://doi.org/10.3390/ polym12010005).

21. Dourado, D. Biomed. J. Sci. Tech. Res., 2019, 22 (3), pp 16634-16636 (http://dx.doi.org/10.26717/ BJSTR.2019.22.003745).

22. Munjal, B.; Suryanarayanan, R. TrAC Trends Anal. Chem., 2021, 136, pp 116-181 (https://doi. org/10.1016/j.trac.2021.116181).

23. Amaya-Chantaca, N. J. Asian Journal of Applied Science and Technology (AJAST), 2020, 4 (2), pp 108-114 (Available at SSRN: https://ssrn.com/abstract=3712886).

24. Delaney, S. P.; Nethercott, M. J.; Mays, C. J.; Winquist, N. T.; Arthur, D.; Calahan, J. L.; Sethi, M.; Pardue, D. S.; Kim, J.; Amidon, G.; et al. Journal of Pharmaceutical Sciences, 2017, 106 (1), 338-347 (https://doi.org/10.1016/j.xphs.2016.10.004).

25. Biçer, A.; Taslimi, P.; Yakalı, G.; Gülçin, I.; Gültekin, M. S.; Cin, G. T. Bioorg. Chem., 2019, 82, pp 393404 (https://doi.org/10.1016/j.bioorg.2018.11.001).

26. Farmacopeia Brasileira, Agência Nacional de Vigilância Sanitária (ANVISA), Brasília, 2019, $6^{\text {th }}$ edition, Volume I. Available at: https://www.gov.br/anvisa/pt-br/assuntos/farmacopeia/farmacopeia-brasileira/ arquivos/7985json-file-1 [Accessed on: March 29, 2021]. 


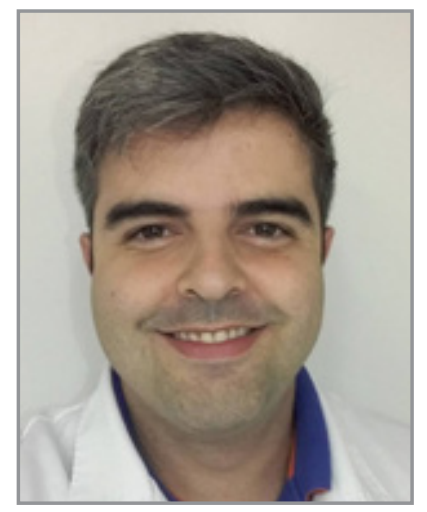

Renan M. B. Dezena is a Preformulation Specialist with Graduation in Pharmaceutical Sciences from Pontifical Catholic University of Campinas (PUC-Campinas), Brazil (2010), and Specialization in Management of Research and Development of Drugs through the Institute of Sciences, Technology and Quality (ICTQ), Brazil (2014). He has 12 years of experience in the Pharmaceutical Industry with background in the Departments of Production, Quality Control and Research \& Development. Perform Preformulation Studies related to the development of pharmaceutical products through the following analytical techniques: Mass spectrometry (LC-MS/MS), Infrared Spectroscopy (MIR and NIR), Ultraviolet Spectroscopy, Liquid Chromatography (HPLC and UPLC), Gas Chromatography (GC-MS), Differential Scanning Calorimetry (DSC), Thermogravimetric Analysis (TGA), X-Ray Powder Diffraction (XRPD), Optical Microscopy, Particle Size Distribution by Laser Diffraction, Confocal Raman Microscopy, Nuclear Magnetic Resonance Spectroscopy, Zeta Potential and Dynamic Light Scattering. 